US Army Corps

of Engineers ${ }_{\circledast}$

Engineer Research and

Development Center

Effects of Milling on the Metals Analysis of Soil Samples Containing Metallic Residues

Jay L. Clausen, Samuel A. Beal, T. Georgian, K.H. Gardner,

July 2021

T.A. Douglas, and Ashley M. Mossell 
The U.S. Army Engineer Research and Development Center (ERDC) solves the nation's toughest engineering and environmental challenges. ERDC develops innovative solutions in civil and military engineering, geospatial sciences, water resources, and environmental sciences for the Army, the Department of Defense, civilian agencies, and our nation's public good. Find out more at www.erdc.usace.army.mil.

To search for other technical reports published by ERDC, visit the ERDC online library at https://erdclibrary.on.worldcat.org/discovery. 


\section{Effects of Milling on the Metals Analysis of Soil Samples Containing Metallic Residues}

Jay L. Clausen, Samuel A. Beal, T. Georgian, K.H. Gardner, T.A. Douglas, Ashley M. Mossell

Cold Regions Research and Engineering Laboratory

U.S. Army Engineer Research and Development Center

72 Lyme Road

Building 4070

Hanover, NH 03755

Fort Wainwright, AK 99703

T. Georgian

U.S. Army Corps of Engineers

1616 Capital Avenue

Omaha, NE 68102

K.H. Gardner

Department of Civil and Environmental Engineering

University of New Hampshire

Durham, NH 03824

Final report

Approved for public release; distribution is unlimited.

Prepared for U.S. Army Corps of Engineers

Washington, DC 201314 


\section{Preface}

This study was based on the results of a privately funded $\mathrm{PhD}$ dissertation using data from multiple projects funded from different sources. The research did not receive any specific grant from funding agencies in the public, commercial, or not-for-profit sectors.

The work was performed by the Biogeochemical Sciences Branch (Mr. Nathan Lamie, Chief) of the Research and Engineering Division (Dr. George Calfas, Chief), U.S. Army Engineer Research and 'Development Center, Cold Regions Research Engineering Laboratory (ERDC-CRREL). At the time of the initial publication, the Deputy Director for ERDC-CRREL was Mr. David Ringelberg and the Director was Dr. Joseph Corriveau.

This article was originally published online in the Microchemical Journal on 8 January 2020.

The Commander of ERDC was COL Teresa A. Schlosser and the Director was Dr. David W. Pittman.

DISCLAIMER: The contents of this report are not to be used for advertising, publication, or promotional purposes. Citation of trade names does not constitute an official endorsement or approval of the use of such commercial products. All product names and trademarks cited are the property of their respective owners. The findings of this report are not to be construed as an official Department of the Army position unless so designated by other authorized documents. 


\section{Effects of milling on the metals analysis of soil samples containing metallic residues}

\begin{abstract}
A B S T R A C T
Metallic residues are distributed heterogeneously onto small-arms range soils from projectile fragmentation upon impact with a target or berm backstop. Incremental Sampling Methodology (ISM) can address the spatially heterogeneous contamination of surface soils on small-arms ranges, but representative kilogram-sized ISM subsamples are affected by the range of metallic residue particle sizes in the sample. This study compares the precision and concentrations of metals in a small-arms range soil sample processed by a puck mill, ring and puck mill, ball mill, and mortar and pestle prior to analysis. The ball mill, puck mill, and puck and ring mill produced acceptable relative standard deviations of less than $15 \%$ for the anthropogenic metals of interest (Lead ( $\mathrm{Pb}$ ), Antimony (Sb), Copper ( $\mathrm{Cu}$ ), and Zinc ( $\mathrm{Zn})$ ), with the ball mill exhibiting the greatest precision for $\mathrm{Pb}, \mathrm{Cu}$, and Zn. Precision by mortar and pestle, without milling, was considerably higher ( $40 \%$ to $>100 \%)$ for anthropogenic metals. Median anthropogenic metal concentrations varied by more than $40 \%$ between milling methods, with the greatest concentrations produced by the puck mill, followed by the puck and ring mill and then the ball mill. Metal concentrations were also dependent on milling time, with concentrations stabilizing for the puck mill by $300 \mathrm{~s}$ but still increasing for the ball mill over $20 \mathrm{~h}$. Differences in metal concentrations were not directly related to the surface area of the milled sample. Overall, the tested milling methods were successful in producing reproducible data for soils containing metallic residues. However, the effects of milling type and time on concentrations require consideration in environmental investigations.
\end{abstract}

\section{Introduction}

Small-arms ranges worldwide are used for training with weapon systems that result in the release of projectile fragments containing antimony (Sb), copper ( $\mathrm{Cu})$, lead ( $\mathrm{Pb})$, and zinc $(\mathrm{Zn})[1,2]$. A significant amount of metal, principally $\mathrm{Pb}$, is deposited to surface soils. Approximately 2 million tons/year of lead are deposited to target range soils every year in the U.S. [3]. The resulting surface soil concentrations up to percent levels $[1,3]$ present an internationally recognized environmental problem [4-6]. Prior studies of organic energetic compounds found conventional grab sampling does not address the heterogeneous distribution of particulates on military training ranges. This leads to nonreproducible mean contaminant concentration estimates with large uncertainty $[7,8]$. Subsequently, conventional grab (i.e., discrete) sampling, was questioned for addressing metal contamination in the environment $[9,10]$. Clausen et al. [9] demonstrated a large number of grab samples ( $n>35$ at a minimum and preferably as many as several hundred) would be needed to address the large degree of spatial variability on small-arms ranges. The high uncertainties in metal concentrations associated with grab samples propagate to calculated exposure point concentrations used in risk assessments [11].

Research on the distribution and sampling of energetic residues at firing points and on impact areas led to recommendations [12-15] and modifications to U.S. Environmental Protection Agency (USEPA) Method 8330 [16] for the sampling and processing of soil, resulting in an update to the Method (8330B) [17]. Collectively, the modifications to the field sampling and sample processing methods are referred to as the Incremental Sampling Methodology (ISM), multi-incremental sampling (MIS) ${ }^{\mathrm{TM}}$, or Incremental Sampling (IS) $[12,13,18]$, which is based on Pierre Gy's sample theory for materials consisting of particulates 
[19-21] Gy's sample theory focuses on minimizing seven sampling errors; (1) fundamental, (2) grouping and segregation, (3) long-range heterogeneity, (4) periodic heterogeneity, (5) increment delimitation, (6) increment extraction, and (7) sample preparation. A direct cause of fundamental error is due to compositional heterogeneity, which is the difference in composition of individual soil particles composing the population and the parameter of interest. The distributional heterogeneity of the contaminant of interest results in the grouping and segregation error. Francis Pitard translated Gy's work to English and discusses these specifics errors and the mechanisms to address and reduce the errors [22]. Pitard summarizes this as "Incremental sampling methodology (ISM) is a structured composite sampling and processing protocol that reduces data variability and provides a reasonably unbiased estimate of mean contaminant concentrations in a volume of soil targeted for sampling" [13]. ISM involves the collection of tens to hundreds of discrete field increments from a defined area of interest (typically referred to as the "Decision Unit [DU]") composited into a single sample and modifica-tions to the sample processing procedures [13]. The sample processing modifications as compared to conventional grab sampling include air-drying, sieving, milling, changes to the sample aliquot mass, and sub-sampling.

The ISM approach allows for an estimate of the mean contaminant concentration when particulates are present in environmental media (e.g., soils and sediments) having a large compositional and distributional heterogeneity [13]. The Department of Defense (DoD), the regulatory community, and environmental consultants are now using ISM for analytes other than energetics, including metals [13,18,23-25]. Comparison studies between grab and ISM have demonstrated less uncertainty [26] and lower sampling errors [27] associated with ISM samples.

Despite the desire for the use of ISM, information on appropriate milling devices or the milling interval necessary for soils containing metallic residues is nonexistent. Milling is one of the principal steps to address contaminant heterogeneity and is one step of the ISM process [13]. Milling is not a common sample preparation process [28,29] and is not specified in USEPA Method 3050B, 3051, or 3052 [16,30,31], methods commonly followed to prepare solid samples. Clausen et al. [32] showed simply collecting multiple increments in the field to form a composite sample only addresses distributional heterogeneity in the soil substrate, a finding consistent with Gy's sample theory [33,34]. Milling is necessary to address the compositional or constitutional heterogeneity for soils containing metallic residues [35,36], as well as energetics $[12,37,38]$, by reducing the subsampling uncertainty prior to analysis. However, most milling equipment has metallic surfaces exposed to the sample during the milling process, which can result in contamination of the sample during processing [39]. A recent study by Clausen et al. [9] used glass beads and a contaminated soil from a small-arms range to show significant metal cross-contamination from a puck mill for chromium (Cr), vanadium (V), and nickel (Ni). However, since the predominant metals of interest at small-arms ranges include $\mathrm{Pb}, \mathrm{Sb}, \mathrm{Cu}$, and $\mathrm{Zn}[1,11,37,38]$, there may be little to no risk of crosscontamination for these metals.

A potential side-effect of sample milling is the enhancement of acid extraction efficiency through the increase in the surface area of metallic residues, soil particles, and mineral grains present in a sample. A recent study focused on the $>2 \mathrm{~mm}$ size fraction of an urban soil suggests milling does result in a significant concentration increase of many trace metals [33]. The two commonly used EPA methods 3050 and 3051 employ nitric and hydrochloric acids on a hot block (3050) and in open vessels in a microwave (3051) to dissolve metals for later analysis. These two methods have yielded complete or nearly complete recovery of many metals (i.e., $\mathrm{Pb}, \mathrm{Cu}, \mathrm{Zn}$ ) in finely ground standard reference materials, specifically National Institute of Standards and Technology (NIST) 2711, a Montana soil. However, extraction in coarser material is likely limited by the availability of soluble surfaces for interaction with acids. By reducing particle size, milling increases sample surface area and potentially leads to greater metal concentrations. In addition, milling enhances the dissolution of some metals containing an insoluble oxide layer that would otherwise remain intact post extraction. However, studies conducted by Felt et al. [39] using "clean" (native) soils milled with equipment containing nonmetallic milling surfaces (mortar and pestle, ball mill, and pulverisette) suggest minimal enhancement to extraction efficiencies by sample milling. Similarly, studies by Clausen et al. [40] using a contaminated soil, Ottawa sand, and glass beads found a puck mill with metallic components yielded only a slight increase in concentrations of most metals (10\% to $30 \%$ ) compared with an unmilled split sample following the standard Method 3050B [16]. Studies using soil from a small-arms range suggests milling increases the $\mathrm{Sb}, \mathrm{Cu}$, and $\mathrm{Pb}$ concentrations due to an increased extraction efficiency of the pure metal fragments [9].

Multiple variables in milling procedures, including equipment type, material, and milling time, may affect reproducibility and mean metal concentrations. Felt et al. [39] found a mortar and pestle and a pulverisette produced more reproducible metal concentrations than a ball mill for uncontaminated soils. In contrast, Clausen et al. [9] obtained acceptable precision (i.e., percent relative standard deviations [RSD] less than 15\%) after ball milling for a longer period of $18 \mathrm{~h}$ (vs. $6 \mathrm{~h}$ in Felt et al. [39]). Here we examined the variables of milling equipment and milling time on subsample reproducibility and mean metal concentration by using a contaminated ISM soil sample from a small-arms range.

\section{Methods}

\subsection{Soil sample collection}

The soil used was obtained in June 2010 from the military smallarms berm face at Range 4-3 located on Camp Ethan Allen in Jericho, Vermont. The berm face is approximately $3 \times 100 \mathrm{~m}$, sparsely vegetated, and composed of loamy sand with gravel and visible small-arms bullet fragments [9]. Range 4-3 is used by Army National Guard units for training with small-arms weapons systems, such as the M16 Rifle that fires a $4.5 \mathrm{~cm}$ long by $5.56 \mathrm{~mm}$ diameter (caliber) projectile round. Clausen et al. $[9,11]$ present additional information on the characteristics of the range. Camp Ethan Allen has a temperate climate with warm, humid summers and cold winters. Monthly daily average temperatures range from $70.6{ }^{\circ} \mathrm{F}\left(21.4^{\circ} \mathrm{C}\right)$ in July to $18.7{ }^{\circ} \mathrm{F}\left(-7.4{ }^{\circ} \mathrm{C}\right)$ in January, and annual precipitation is $36.8 \mathrm{in}$. (935 mm).

A single 200-increment surface soil sample was collected to a depth of $5 \mathrm{~cm}$ using a $2 \mathrm{~cm}$ diameter metal corer [38] following procedures outlined in $[9,10,13]$ yielding a $20 \mathrm{~kg}$ sample. The largest particle size was less than $1 \mathrm{~cm}$ in diameter. Field sampling error was controlled by collecting sufficient mass to reduce the effects of compositional heterogeneity. The long-range and periodic heterogeneity was addressed by collecting a sufficient number of increments, 200, across the sample area of interest. The delimitation error was addressed by collecting a cylindrical volume of material with the corer so that every fragment of the population of interest has an equal probability of being included in the sample. A cylindrical corer also allows for a consistent depth of sample recovery for every increment. The corer diameter size selected ensured that no soil particulate was excluded from the sample. Equipment rinseate samples have previously demonstrated no cross-contamination from the soil corer [9]. .

\subsection{Sample preparation and milling methods}

The $20 \mathrm{~kg}$ sample was sent to the U.S. Army Cold Regions Research and Engineering Laboratory (CRREL) geochemistry laboratory in Hanover, NH, where it was air-dried, and sieved through a no. 10 mesh sieve to remove material larger than $2 \mathrm{~mm}$ diameter $(0.43 \mathrm{~kg}$ of which was set aside). The USEPA does not consider material larger than $2 \mathrm{~mm}$ in size to constitute soil and thus is not analyzed and included in human 
health and ecological risk assessments. Sieving followed by milling did not result in significant bias, although larger concentrations were observed for $\mathrm{Pb}$ and $\mathrm{Cu}$ sample variance was greatly reduced [40]. Following air-drying and sieving a sectorial rotary splitter operated at $100 \mathrm{rpm}$ was used to split the less than $2 \mathrm{~mm}$ material in half. Previous work has demonstrated the superiority of the sectorial splitter yielding representative sample as compared to other mass reduction techniques [41]. Half of the material, $10 \mathrm{~kg}$, was used in earlier experiments described in Clausen et al. [11,26,32].

Subsample replicates of the unmilled $10 \mathrm{~kg}$ soil were obtained by spreading the soil on a flat surface produced a layer 1 to $2 \mathrm{~cm}$ thick. A total of 15 replicate subsamples of this unmilled material were collected using the Japanese slab cake approach by collecting 20 increments in a systematic random fashion (similar to the field sample collection approach) using a flat bottom scoop with sides to yield a $2 \mathrm{~g}$ subsample for digestion and analysis (Unmilled \#1). A flat bottom scoop ensured a consistent volume of soil was obtained from the top and bottom of the soil layer. It was necessary to collect the unmilled sample prior to proceeding with the following sample processing.

The remaining approximate $10 \mathrm{~kg}$ of sieved material was processed through a sectorial rotary splitter operated at $100 \mathrm{rpm}$ to create 12 splits of approximately $0.8 \mathrm{~kg}$ each for the milling experiments. The procedure in USEPA Method 8330B Appendix B [16] was followed to subsample all of the split samples for the milling experiments as described above for the unmilled sample.

Ultrapure reagent-grade acids were used for the digestions combined with deionized water with a resistivity of greater than $10 \mathrm{M} \Omega \mathrm{cm}$. Fifteen replicate subsamples were collected, digested, and analyzed for each milling apparatus. Five splits of sieved material were milled with the following equipment: (1) a Labtech Essa chrome steel puck mill grinder (Model LM2, B elmont,Australia) at APPL Inc. (Clovis, CA)(Puck Mill \#1); (2) a Labtech Essa chrome steel puck mill grinder (Model LM2, B elmont,Australia) at CRREL (Puck Mill \#2); (3) a chrome steel TM Engineering ring and puck mill grinder (Model TM/S) at Test America (Denver, CO) (Puck \& Ring Mill); (4) a Stoneware roller mill (Model $803 \mathrm{FVM}$ ) with polyurethane coated steel jars and agate milling stones at Test America (Denver, CO) (B all Mill); and (5) a ceramic mortar and pestle at CRREL (Mortar \& Pestle). One split of sieved material was not milled (Unmilled \#2). Table 1 summarizes relevant parameters for each milling technique.

The composition of the Labtech Essa bowl and puck principally consists of $\mathrm{Cr}$ and $\mathrm{Fe}$, with lesser amounts of $\mathrm{Mn}(0.37 \%)$, Ni $(0.30 \%)$, $\mathrm{Cu}(0.20 \%), \mathrm{Zn}(52 \mathrm{mg} / \mathrm{kg}), \mathrm{Sb}(18 \mathrm{mg} / \mathrm{kg})$, and $\mathrm{Pb}(7 \mathrm{mg} / \mathrm{kg})$ [10] The Labtech Essa puck mills can accommodate up to $800 \mathrm{~g}$ of material and mill a sample to a $75 \mu \mathrm{m}$ particle size. The TM Engineering ring and puck mill can mill up to $500 \mathrm{~g}$ of material in a single batch and has a similar bowl, ring, and puck composition as the Labtech Essa components. The Stoneware ceramic ball mill can accommodate up to six sample jars and is operated at $290 \mathrm{rpm}$. The mortar and pestle is composed of glazed, hard, chemical-resistant porcelain and can accommodate up to $70 \mathrm{~g}$ of material per batch. Manual disaggregation with the mortar and pestle involved multiple batches combined to form a single processed sample.

Table 1

Five different sample processing methods with milling times and relevant analytical parameters for comparison test.

\begin{tabular}{llll}
\hline Milling technique & Milling time (s) & Analysis method & Digestion acids \\
\hline Ball Mill & 64,800 & ICP-MS & $\mathrm{HNO}_{3}$ \\
Mortar \& Pestle & 300 & ICP-OES & $\mathrm{HNO}_{3}+\mathrm{HCl}$ \\
Puck \& Ring Mill & 300 & ICP-MS & $\mathrm{HNO}_{3}$ \\
Puck Mill \#1 & 300 & ICP-MS & $\mathrm{HNO}_{3}$ \\
Puck Mill \#2 & 300 & ICP-OES & $\mathrm{HNO}_{3}+\mathrm{HCl}$ \\
Unmilled \#1 & 0 & ICP-MS & $\mathrm{HNO}_{3}$ \\
Unmilled \#2 & 0 & ICP-OES & $\mathrm{HNO}_{3}+\mathrm{HCl}$ \\
\hline
\end{tabular}

The splits for the two puck mills, puck and ring mill, and mortar and pestle were milled over five 60 -s intervals (300 s total milling time) with $60 \mathrm{~s}$ of cooling between each interval. The ball mill sample split was milled continuously for $18 \mathrm{~h}$.

\subsection{Sample analysis}

The split samples shipped to APPL and Test America for milling were subsampled, digested, and analyzed at their respective laboratories following the procedures above. The CRREL experimental samples were subsampled in-house and then shipped to the USACE Environmental Laboratory (EL) in Vicksburg, MS, for digestion and analysis. Each laboratory used the same digestion protocol (Method 3050B) and analysis protocol (Method 6020, [42]). Analysis at APPL Inc. was performed on an Agilent 7500cx ICP-MS with the following setting: $\mathrm{RF}$ power at torch $=1600 \mathrm{~W}$, carrier gas flow $=1 \mathrm{~L} / \mathrm{min}$., auxiliary gas flow $=0.1 \mathrm{~L} / \mathrm{min}$., nebulizer flow $=0.4 \mathrm{~mL} / \mathrm{min}$., and pump flow rate $=0.1 \mathrm{rpm}$. Analysis at Test America was performed on an Agilent 7500 series ICP-MS operated in the collision-cell mode, with helium as the collision gas. Samples at EL were analyzed with a Perkin Elmer Sciex ELAN 6000 ICP-MS. The quantification limits for most metals were approximately $1 \mathrm{mg} / \mathrm{kg}$. Surface area was measured on duplicate subsamples of certain splits using Brunauer-Emmett-Teller (BET) adsorption with nitrogen gas.

\section{Data analysis}

Precision was assessed by RSDs calculated as the standard deviation divided by the mean. Differences in variances between milling techniques were derived from Levene's test, and differences in concentrations derived from Kruskal-Wallis analysis of variance with BenjaminiHochberg p-value correction. Concentration differences between individual milling techniques were assessed using the Conover-Iman test.

\section{Results and discussion}

\subsection{Comparison of milling techniques}

The performance of each milling technique in producing reproducible metal concentrations was evaluated based on a target RSD of less than $15 \%$ for the 15 replicates [13]. The two unmilled splits yielded RSDs varying from 17 to $257 \%$ for $\mathrm{Cu}, \mathrm{Pb}, \mathrm{Sb}$, and $\mathrm{Zn}$ (Fig. 1). These high RSDs are a result of the unpredictability in the number of particulates present in any given subsample, despite implementing the incremental subsampling approach. The presence (or absence) of a single large particle in any one increment could have a significant impact on the resultant metal concentration. For example, the range in $\mathrm{Cu}$ concentrations for the Unmilled \#1 samples vary from 299 to 10,900 $\mathrm{mg} / \mathrm{kg}$ (Supporting Material). The precision for the mortar and pestle was also above the $15 \%$ RSD target, varying from 28 to 55\%, reflecting this technique's tendency for disaggregation rather than pulverization. Pulverization involves reducing the particle size of the individual soil grains and any metallic residues, whereas disaggregation involves physical separation of cohesive soil grains.

The puck mill, ring and puck mill, and ball mill each yielded results meeting our performance criteria for the anthropogenic metals of interest $\mathrm{Cu}, \mathrm{Pb}, \mathrm{Sb}$, and $\mathrm{Zn}$ (Fig. 1). The one exception being an RSD of $21 \%$ for $\mathrm{Sb}$ in the Puck Mill \#1 samples. Increased precision indicates the milling techniques adequately reduced total sample error due to heterogeneity by increasing the number of metal particles in the sample and improving the probability of subsampling a consistent number of residue particles, consistent with Gy's theory [20]. In contrast, the RSDs for lithogenic metals were below $15 \%$ for all milling techniques, including unmilled splits, which reflects the homogeneous distribution of these metals in the native soil matrix (Supporting Material). These results indicate milling is required for samples with anthropogenic 


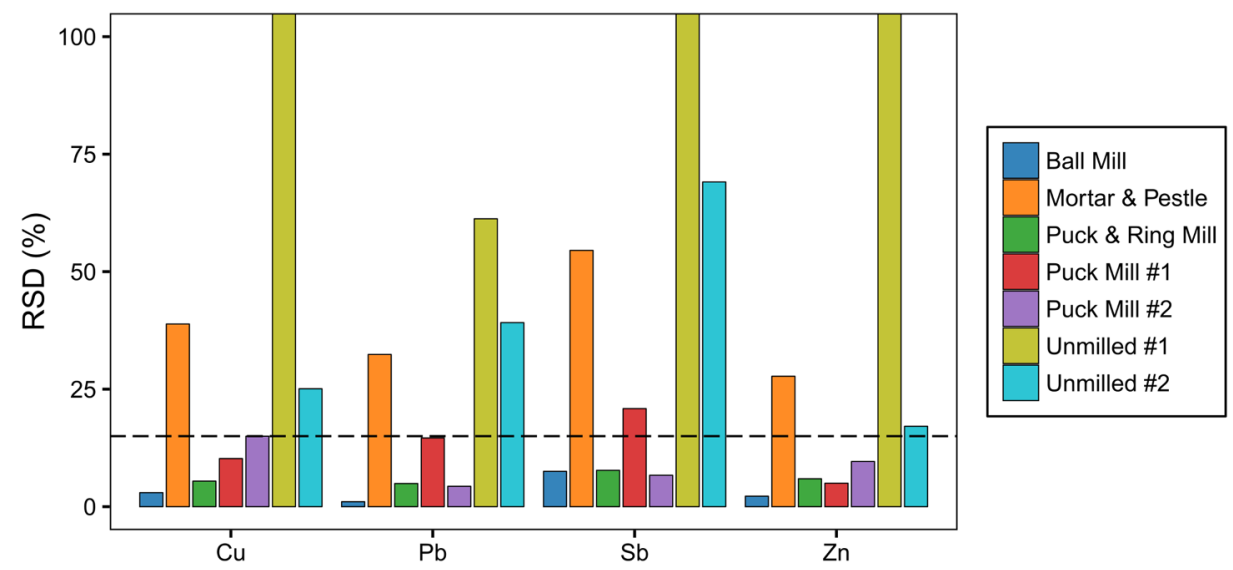

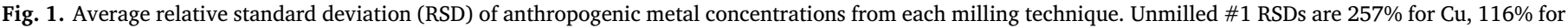
$\mathrm{Sb}$, and $162 \%$ for $\mathrm{Zn}$. Acceptance level of $15 \%$ RSD is shown as a dashed line.

metallic residues when the composition of those residues are of interest.

The concentrations of anthropogenic metals vary significantly (Kruskal-Wallis $p<1 \times 10^{-14}$ ) between milling techniques (Table 2, Fig. 2). For $\mathrm{Pb}$, the two puck mills produced the greatest concentrations, followed by the ring and puck mill for which metals concentrations were greater than the ball mill (Conover-Iman $p<0.003$ ). There were no statistically significant differences between the two unmilled techniques and the mortar and pestle for $\mathrm{Pb}$. The higher $\mathrm{Pb}$ concentrations for the puck mills may be related to the intense force this technique places on sample grains, which may increase surface area and digestion efficiency. Puck Mill \#2 produced the greatest $\mathrm{Sb}$ concentrations (Conover-Iman $p<0.0001$ ).However, Puck Mill \#1 had concentrations greater than the ball mill and puck and ring mill, but not different from the mortar and pestle and unmilled splits. The ball mill had the lowest $\mathrm{Sb}$ concentrations of any of the tested techniques. The difference in $\mathrm{Sb}$ concentrations may reflect the usage of hydrochloric acid in digestion for Puck Mill \#2 (analyzed by ICP-OES) but not for Puck Mill \#1 (analyzed by ICP-MS). Analysis with the ICP-OES requires the use of hydrochloric acid whereas the ICP-MS does not. Digestion with hydrochloric acid has been shown to greatly improve Sb recovery. Similarly, hydrochloric acid was not used for the ball mill, puck and ring mill, and Unmilled $\# 1$, which may explain their relatively low Sb concentrations.

Median $\mathrm{Cu}$ concentrations were 30 to $44 \%$ higher for Puck Mill \#2 than for the other techniques (Conover-Iman $p<0.0001$ ). There were significant differences in $\mathrm{Cu}$ concentrations between some of the other milling techniques, but median differences were low, between 0 and $21 \%$. For Zn, Puck Mill \#2 again had the highest concentrations (Conover-Iman $p<0.0002$ ). The mortar and pestle and unmilled \#1 splits had higher Zn concentrations than the other techniques, but median differences among the other techniques were less than $4 \%$. The higher concentrations of $\mathrm{Cu}$ and $\mathrm{Zn}$ for Puck Mill \#2 are likely not from the chrome steel bowl $(2000 \mathrm{mg} / \mathrm{kg} \mathrm{Cu}$ and $52 \mathrm{mg} / \mathrm{kg} \mathrm{Zn})$, as such

Table 2

Mean \pm one standard deviation of anthropogenic metal concentrations for each milling technique.

\begin{tabular}{lllll}
\hline & $\mathrm{Cu}(\mathrm{mg} / \mathrm{kg})$ & $\mathrm{Pb}(\mathrm{mg} / \mathrm{kg})$ & $\mathrm{Sb}(\mathrm{mg} / \mathrm{kg})$ & $\mathrm{Zn}(\mathrm{mg} / \mathrm{kg})$ \\
\hline $\begin{array}{l}\text { Ball Mill } \\
\text { Mortar \& Pestle }\end{array}$ & $319.3 \pm 9.5$ & $1687 \pm 18$ & $3.47 \pm 0.26$ & $51.6 \pm 1.1$ \\
$\begin{array}{c}\text { Puck \& Ring } \\
\quad \text { Mill }\end{array}$ & $346 \pm 19$ & $2350 \pm 120$ & $5.20 \pm 0.40$ & $50.5 \pm 3.0$ \\
$\begin{array}{l}\text { Puck Mill \#1 } \\
\text { Puck Mill \#2 }\end{array}$ & $279 \pm 29$ & $3040 \pm 440$ & $11.2 \pm 2.3$ & $49.9 \pm 2.5$ \\
Unmilled \#1 & $1000 \pm 2700$ & $2000 \pm 1300$ & $16 \pm 18$ & $80 \pm 140$ \\
Unmilled \#2 & $357 \pm 90$ & $1600 \pm 630$ & $14.2 \pm 9.8$ & $66 \pm 11$ \\
\hline
\end{tabular}

concentration differences would reflect significant erosion of the bowl metal and as the same equipment was used in Puck Mill \#1 and the puck and ring mill, which did not have elevated $\mathrm{Cu}$ and $\mathrm{Zn}$. The extremely high outliers for both $\mathrm{Cu}$ and $\mathrm{Zn}$ in the unmilled samples suggest the presence of particles of $\mathrm{Cu}$ and $\mathrm{Zn}$ in the sieved sample, which may not have been equally distributed during splitting. The relatively consistent and precise $\mathrm{Cu}$ and $\mathrm{Zn}$ concentrations for the ball mill, puck and ring mill, and Puck Mill \#1 indicate complete and reproducible homogenization for these metals. On military small-arms ranges using conventional $\mathrm{Pb}$ munitions, these metals are typically released from the bullet jacket, which may be more easily pulverized than $\mathrm{Pb}$ and $\mathrm{Sb}$, which are typically from the bullet slug.

The magnitude of the effect from milling as it relates to withinsample heterogeneity was calculated for the small arms metals $\mathrm{Pb}, \mathrm{Sb}$, $\mathrm{Cu}$, and $\mathrm{Zn}$ using Glass $\Delta$. For the calculation of Glass $\Delta$, the milled ISM results were viewed as the "control group" and the corresponding laboratory replicate subsamples prior to milling was viewed as the "treatment group." Glass $\Delta$ was calculated by dividing the difference between the means of the "unmilled" replicates and means of the milled by the sample standard deviation of the "control group" (i.e., the standard deviation of the milled replicates):

$\frac{\bar{x}_{1}-\bar{x}_{2}}{s_{2}}$

An effect size is qualitatively considered to be large if it is near or greater than one. As shown in Table 3, for the control of within-sample heterogeneity, the effect size associated with milling for the small arms metals is very large. The effect size will likely be smaller when total measurement variability is taken into account because sample-tosample variability is expected to be larger than within-sample variability. Estimation of the effect size is challenging when there is large variability, because relatively large sample sizes are needed to accurately estimate the mean and standard deviation.

$\mathrm{As} \mathrm{Pb}$ is the major contaminant of concern for small arms ranges and possess the largest effect size associated with within-sample variability, the Glass $\Delta$ effect size was calculated for both ISM and grab samples collected from the same DU (Table 4).

Glass $\Delta=(2758-4411) / 435=-1653 / 435=-3.8$

As shown above, the effect size for $\mathrm{Pb}$ is significantly smaller when total measurement variability is taken into account. However, the magnitude of Glass $\Delta$ suggests milling of the ISM sample still yields a large effect as compared to an unmilled sample.

\subsection{Effect of milling time}

The effect of milling time of resultant concentrations and precision 

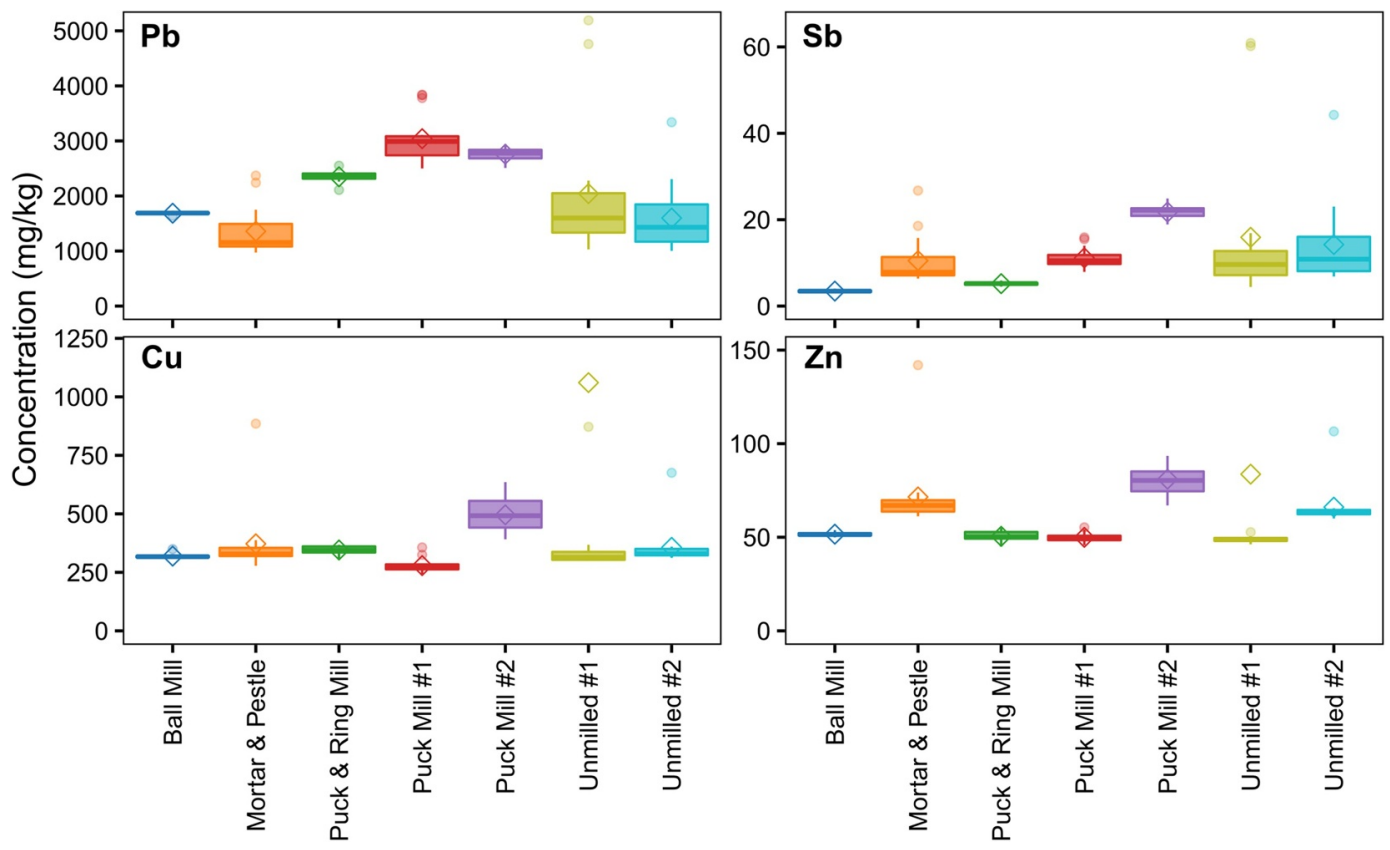

Fig. 2. Boxplots of anthropogenic metal concentrations for each milling method. The Unmilled \#1 method had one sub-sample with outlying $\mathrm{Cu}(10,900 \mathrm{mg} / \mathrm{kg})$ and $\mathrm{Zn}(574 \mathrm{mg} / \mathrm{kg})$ that is not plotted. Median values are shown as bars, 25th and 75th percentiles as hinges, at most 1.5 times the interquartile range from each hinge as whiskers, outliers as points, and means as diamonds.

Table 3

Effect size estimates.

\begin{tabular}{llllllll}
\hline Metal & Mean_U & Mean_M & Mean_U - Mean_M & SD_M & SD_Pool & Glass $\Delta$ \\
\hline $\mathrm{Pb}$ & 1600 & 2720 & -1120 & 119 & 370 & -9.4 \\
$\mathrm{Sb}$ & 14.2 & 22.6 & -8.3 & 1.58 & 5.76 & -5.3 \\
$\mathrm{Cu}$ & 357 & 550 & -193 & 102 & 97.9 & -1.9 \\
$\mathrm{Zn}$ & 66.1 & 77.2 & -11.1 & 8.66 & 9.60 & -1.3 \\
\hline
\end{tabular}

$\mathrm{U}=$ Unmilled data set, $\mathrm{M}=$ Milled data set, $\mathrm{SD}=$ standard deviation.

Table 4

Descriptive statistics for grab and ISM small arms $\mathrm{Pb}$ results from same DU.

\begin{tabular}{llllllll}
\hline Variable & $\mathrm{N}$ & Mean & SE Mean & SD & Minimum & Median & Maximum \\
\hline $\mathrm{Pb}$ _Grab & 36 & 4411 & 2204 & 13227 & 44 & 1245 & 79020 \\
$\mathrm{~Pb} I S M$ & 7 & 2758 & 164 & 435 & 2406 & 2539 & 3595
\end{tabular}

$\mathrm{N}=$ number of samples, $\mathrm{SE}=$ standard error, $\mathrm{SD}=$ standard deviation. was explored using the puck mill and ball mill. Fig. 3 shows anthropogenic metal concentrations after five time intervals for Puck Mill \#2. Acceptable precision of less than 15\% RSD was achieved for all four anthropogenic metallic residue of interest only after the full $300 \mathrm{~s}$ of milling (Fig. 3). Concentrations of each anthropogenic metal tended to increase with milling time (Kruskal-Wallis $p<0.005$ ) and appeared to plateau by $120 \mathrm{~s}$ of puck milling. Overall, the variances of $\mathrm{Pb}, \mathrm{Sb}$, and $\mathrm{Cu}$ decreased as milling time increased (Levene $p<0.0003$ ), suggesting particle size reduction of bullet fragments resulted in a corresponding decrease in total subsampling error. Zinc concentrations seemed to increase with puck milling time (Kruskal-Wallis $p<0.00001$ ), but variances did not change over time (Levene $p=0.37$ ). The general lack of improvement in $\mathrm{Cu}$ and $\mathrm{Zn}$ subsampling precision with milling time may reflect that this material tended to form flat plates rather than be ground to a smaller particle size. The unusual increase in $\mathrm{Zn}$ concentrations between the 120 and 300 s puck milling intervals is not met with a difference in variances ( $F$-test $p=0.28$ ). Overall, a puck milling time of $300 \mathrm{~s}$ is required to achieve acceptable precision and maximum

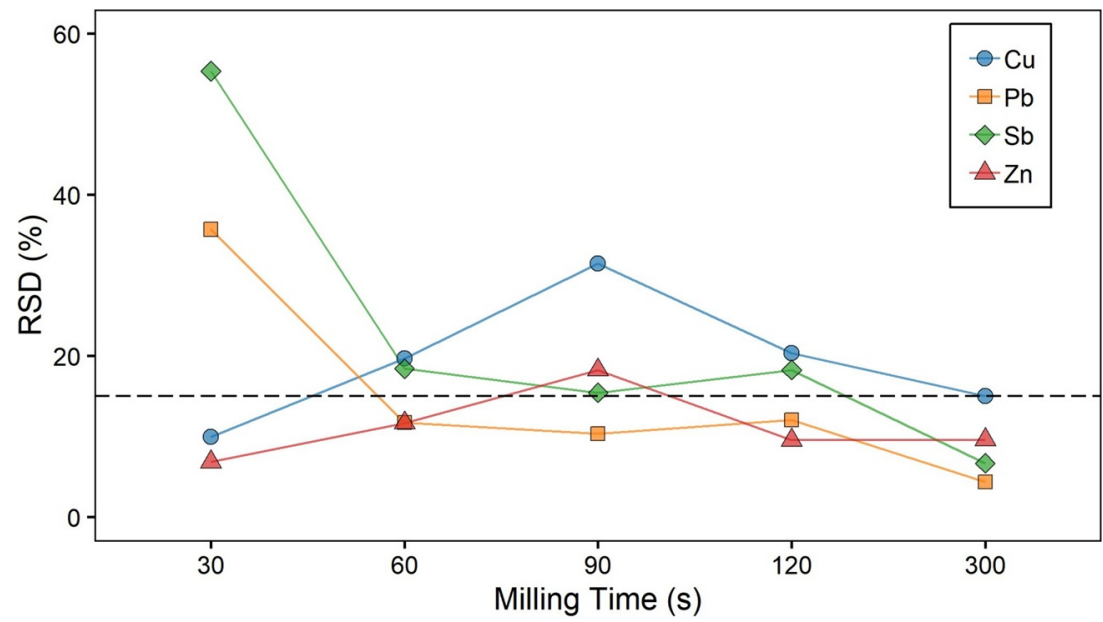

Fig. 3. Effect of puck mill grinding time on method precision. Acceptance level of 15\% RSD is shown as a dashed line. 


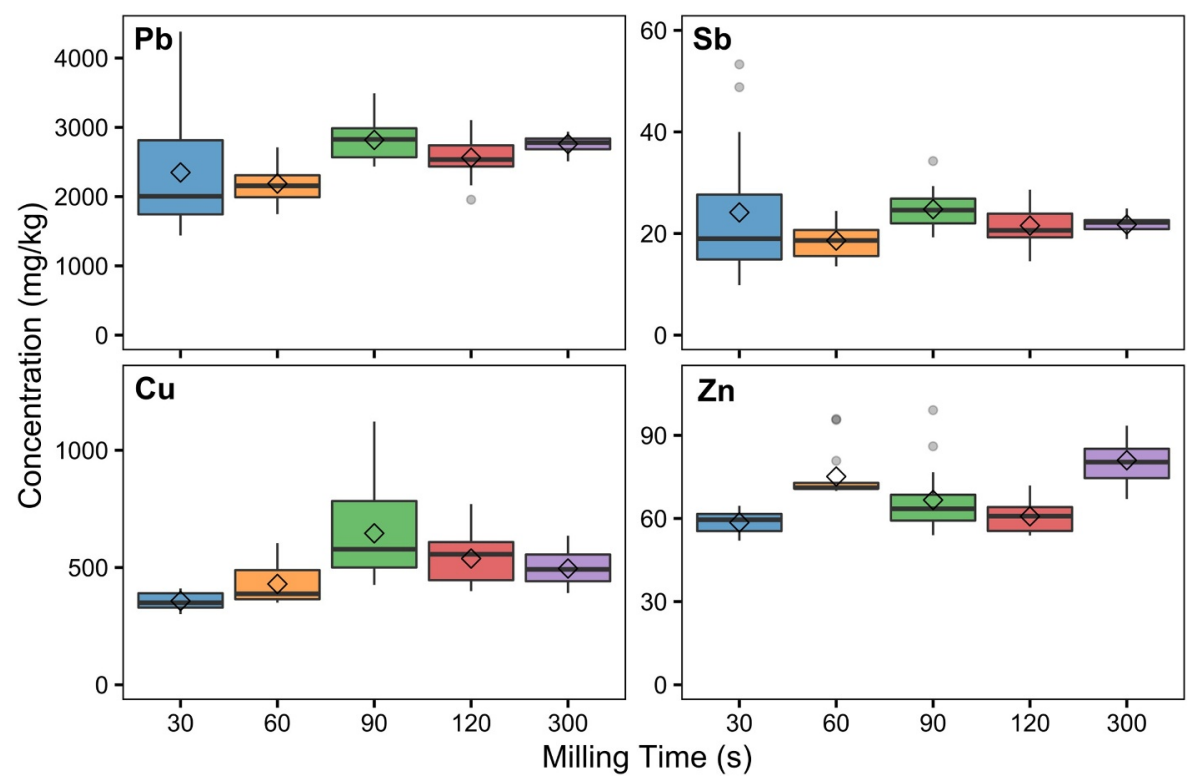

Fig. 4. Effect of puck mill milling time on anthropogenic metal concentrations. Mean values are plotted as diamonds.

concentrations for $\mathrm{Pb}$ and $\mathrm{Sb}$, and to a lesser extent for $\mathrm{Cu}$ and $\mathrm{Zn}$ (Fig. 4). Trends in lithogenic metal concentrations were mostly random, except for the metals $\mathrm{Fe}, \mathrm{Cr}$, and $\mathrm{Ni}$, which are major components of the puck bowl and show a steady increase in concentrations with milling time.

The effect of milling time was also studied using the ball mill on a separate unsieved fraction of the Camp Ethan Allen soil. Unlike the other sieved soil splits that are presented here, this experiment included soil particles greater than $2 \mathrm{~mm}$. A ball milling time of $8 \mathrm{~h}$ produced acceptable precision $(\mathrm{RSD}<15 \%)$ for $\mathrm{Pb}, \mathrm{Cu}$, and $\mathrm{Zn}$ but not for $\mathrm{Sb}$ (Table 5), which may reflect its relative hardness and difficulty in milling. By $12 \mathrm{~h}$, Sb precision was acceptable; and precision for all analytes increased monotonically with milling time. The increase in precision with milling time is consistent with Gy's theory, as extended milling produces an increasing number of metallic particles that subsequently increase the probability of reproducible subsampling [32].

Similar to the observations with the puck mill, an increase in the milling interval with the ball mill resulted in an increase in anthropogenic metal concentrations (Fig. 5), but in lithogenic metals as well (Supporting Material). However, unlike with the puck mill, metal concentrations did not appear to plateau within the tested milling intervals but rather continued to increase through the longest tested interval of $20 \mathrm{~h}$. Consequently, the selection of a 20-h over an 8-h milling time results in median concentrations that were greater by $53 \%$ for $\mathrm{Pb}$, $65 \%$ for $\mathrm{Sb}, 29 \%$ for $\mathrm{Cu}$, and $35 \%$ for $\mathrm{Zn}$. We hypothesize this monotonic increase in metal concentrations with milling time is the result of continuous particle size reduction and a subsequent increase in particle surface area and associated digestion efficiency.

Table 5

Precision of anthropogenic metallic residue results for varying ball milling intervals.

\begin{tabular}{lllll}
\hline Time (h) & \multicolumn{2}{l}{ RSD (\%) } & & \\
\cline { 2 - 5 } & $\mathrm{Pb}$ & $\mathrm{Sb}$ & $\mathrm{Cu}$ & $\mathrm{Zn}$ \\
\hline 8 & 10.0 & 19.7 & 5.6 & 3.6 \\
12 & 3.9 & 7.2 & 3.8 & 3.5 \\
16 & 1.4 & 6.8 & 3.0 & 2.5 \\
20 & 1.1 & 2.1 & 1.8 & 1.3 \\
\hline
\end{tabular}

\subsection{Surface area effects}

By reducing particle size, milling not only increases precision by increasing the number of metallic particles but also may increase metal concentrations by increasing surface area. Increased surface area of metallic and soil particles likely increases the efficiency of acid digestions, resulting in greater analyzed concentrations. Milling increased surface areas dramatically compared with unmilled material (Fig. 6). The general disaggregation caused by the mortar and pestle resulted in surface areas that were approximately 3 to 5 times lower than the other milling techniques. Surface area generally increased with puck milling time but slightly decreased between the 120 and 300 s intervals, potentially indicative of aggregation or particle welding. Overall, processing the sample with the puck and ring mill yielded particles with the largest surface areas, followed by the ball mill. However, despite these high surface areas, the puck and ring mill and ball mill had $\mathrm{Pb}$ and $\mathrm{Sb}$ concentrations that were significantly less than the puck mills (Fig. 2). One potential explanation for this disparity is that the puck and ring mill and ball mill, being less vigorous in milling than the puck mills, reduced the particle size of primarily the soil matrix and to a lesser degree the bullet slug particles that contained $\mathrm{Pb}$ and $\mathrm{Sb}$, whereas the puck mill milling process is more aggressive and results in greater abrasion of the bullet particles. The effect of ball milling time on metal concentrations suggests that more than $20 \mathrm{~h}$ will be necessary to match the reduction in metallic residue particles produced by the puck mills.

\section{Conclusions}

This study showed the necessity of milling soils containing metallic residues. Unmilled subsamples, as well as soil processed with the mortar and pestle, resulted in metal concentrations with unacceptably high RSDs. The puck mill, puck and ring mill, and ball mill all exhibited acceptable RSDs; however, both the precision and resultant metal concentrations depended on the milling time used. A puck milling time of $300 \mathrm{~s}$ and ball milling time of $12 \mathrm{~h}$ was needed to achieve acceptable RSDs less than 15\%; but whereas anthropogenic metal concentrations stabilized after $300 \mathrm{~s}$ of puck milling, they continued to increase through $20 \mathrm{~h}$ of ball milling time. A study with longer ball milling times is needed to determine if and when concentrations stabilize. Differences in resultant metal concentrations we hypothesized are the result from differences in soil particle sizes and associated surface area and 


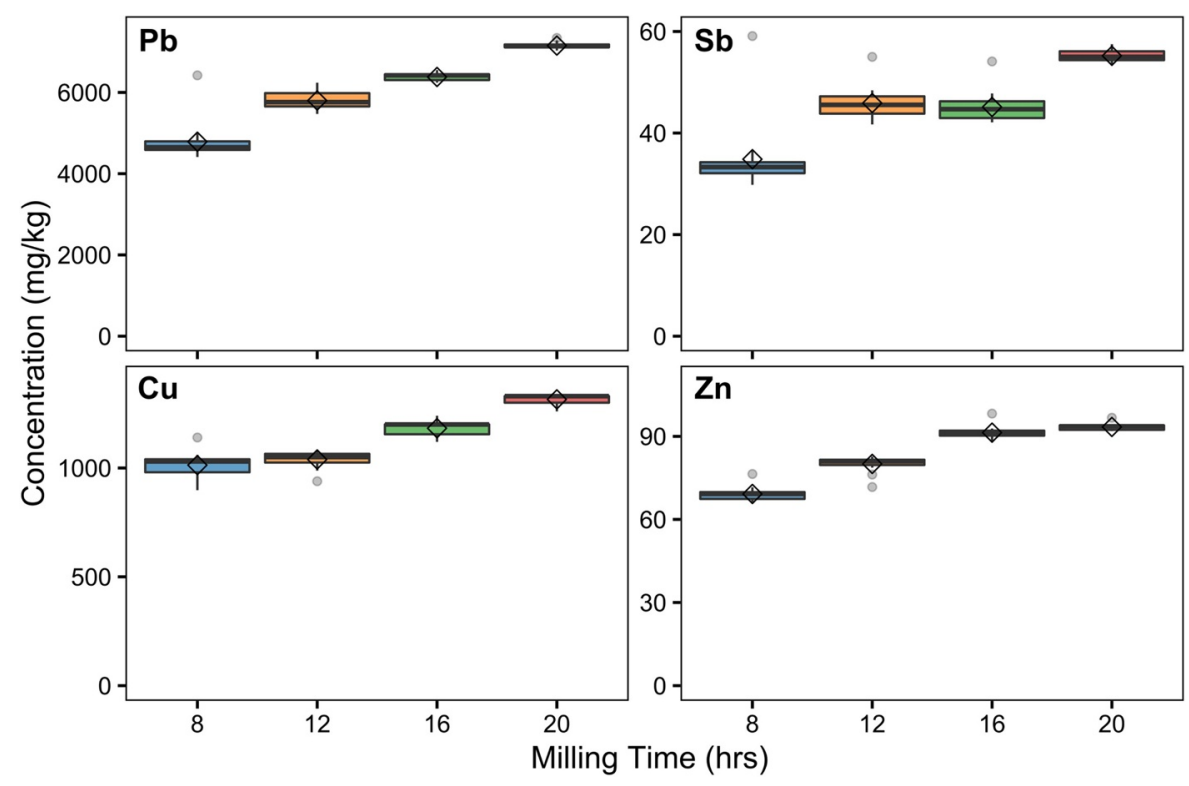

Fig. 5. Effect of ball mill milling time on anthropogenic metal concentrations. Mean values are plotted as diamonds. The fraction used in this test was unsieved and is therefore not directly comparable with the other, sieved data presented here.

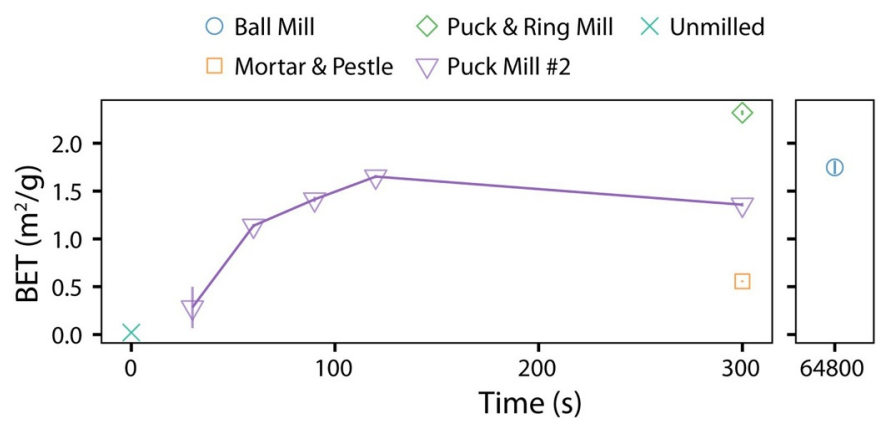

Fig. 6. Effect of milling time on surface area for each milling method. Error bars are \pm 1 standard deviation.

digestion efficiency. However, the puck mills exhibited the highest $\mathrm{Pb}$ and $\mathrm{Sb}$ concentrations but had surface areas less than those produced by the puck and ring mill and the ball mill. The actual surface areas of metallic particles within the soil matrix may not co-vary with the overall surface area of the soil sample. Confirmation by particle size analysis and/or size-resolved metal analysis (i.e., Field Flow Fractionation ICP-MS) would support the hypothesis that the impact of the puck mill is more efficient at reducing the particle size of small-arms residues. The dependence of metal concentration data on the milling method, combined with the wide range of milling methods in use, cautions the direct comparison of data produced from different milling methods.

\section{Novelty statement}

The novelty discussed in the paper is a comparison of different types of milling equipment and the resulting precision from grinding soils from small arms ranges. The paper also documents the milling time necessary to achieve acceptable precision levels for sample processing of heterogeneously contaminated soils.

\section{Declaration of Competing Interests}

The authors declare that they have no known competing financial interests or personal relationships that could have appeared to influence the work reported in this paper.

\section{Acknowledgments}

The research presented in this paper is from a thesis submitted to the Graduate School at the University of New Hampshire as part of the requirements for completion of a doctoral degree. This research did not receive any specific grant from funding agencies in the public, commercial, or not-for-profit sectors.

\section{Supplementary materials}

Supplementary material associated with this article can be found, in the online version, at doi:10.1016/j.microc.2019.104583.

\section{References}

[1] J. Clausen, N. Korte, The distribution of metals in soils and pore water at three U.S. military training facilities, Soil Sedim. Contam. J. 18 (5) (2009) 546-563.

[2] J.L. Clausen, J. Robb, D. Curry, N. Korte, A case study of contaminants on military ranges: camp Edwards, Massachusetts, USA, Environ. Pollut. 129 (2004) 13-21.

[3] USEPA, Best Management Practices for Lead at Outdoor Shooting Ranges, Division of Enforcement and Compliance Assistance, RCRA Compliance Branch, New York, NY, 2005 U.S. Environmental Protection Agency. EPA-02-B-01-001.

[4] L. Knechtenhofer, I. Xifra, A. Scheinost, H. Flühler, R. Kretzschmar, Fate of heavy metals in a strongly acidic shooting-range soil: small-scale metal distribution and its relation to preferential water flow, J. Plant Nutr. Soil Sci. 166 (2002) 84-92.

[5] A. Scheinost, A. Rossberg, D. Vantelon, I. Xifra, R. Kretzschmar, L. A-K, H. Funke, C.A. Johnson, Quantative antimony speciation in shooting-range soils by EXAFS spectroscopy, Geochim. Cosmochim. Acta 70 (13) (2006) 3299-3312.

[6] J. Sorvari, R. Antikainen, O. Pyy, Environmental contamination at finnish shooting ranges-the scope of the problem and management options, Sci. Total Environ. 366 (1) (2006) 21-31.

[7] T.F. Jenkins, C.L. Grant, G.S. Brar, P.G. Thorne, P.W. Schumacher, T.A. Ranney, Sampling error associated with collection and analysis of soil samples at TNT contaminated sites, Field Anal. Chem. Technol. 1 (1997) 151-163.

[8] T.F. Jenkins, A.D. Hewitt, M.E. Walsh, T.A. Ranney, C.A. Ramsey, C.L. Grant, K.L. Bjella, Representative sampling for energetic compounds at military training ranges, Environ. Forensics 6 (2005) 45-55.

[9] J.L. Clausen, T. Georgian, J. Richardson, A. Bednar, N. Perron, L. Penfold, D. Anderson, G. Gooch, T. Hall, E. Butterfield, Evaluation of Sampling and Sample Preparation Modifications for Soil Containing Metal Residues, US Army Corps of Engineers, Environmental Research and Development Center, Cold Regions Research and Engineering Laboratory, Hanover, NH, 2012 ERDC TR-12-1 http:// acwc.sdp.sirsi.net/client/search/asset:asset?t:ac $=\$ N / 1006020$.

[10] J.L. Clausen, T. Georgian, A. Bednar, N. Perron, A. Bray, P. Tuminello, G. Gooch, N. Mulherin, A. Gelvin, M. Beede, S. Saari, W. Jones, S. Tazik, Demonstration of Incremental Sampling Methodology for Soil Containing Metallic Residues, US Army Corps of Engineers, Environmental Research and Development Center, Cold Regions Research and Engineering Laboratory, Hanover, NH, 2013 ERDC/CRREL TR-13-9 http://acwc.sdp.sirsi.net/client/search/asset/1030080. 
[11] J. Clausen, T. Georgian K. Gardner, T. Douglas, Applying incremental sampling methodology to soils containing heterogeneously-distributed metallic residues in order to improve risk analysis, Bull. Environ. Contam. Toxicol. 100 (1) (2018) 155-161, https://doi.org/10.1007/s00128-017-2252-x.

[12] A.D. Hewitt, T.F. Jenkins, M.E. Walsh, S.R. Bigl, S. Brochu, Validation of Sampling Protocol and the Promulgation of Method Modifications for the Characterization of Energetic Residues on Military Testing and Training Ranges, US Army Corps of Engineers, Environmental Research and Development Center, Cold Regions Research and Engineering Laboratory, Hanover, NH, 2009 ERDC/CRREL TR-09-6.

[13] ITRC, Technical and Regulatory Guidance: Incremental Sampling Methodology, Interstate Technology and Regulatory Council, Incremental Sampling Methodology Team, Washington, DC, 2012 ISM-1 http://itrcweb.org/ism-1/.

[14] S. Thiboutot, G. Ampleman, P. Dube, J. Hawari, B. Spencer, L. Paquet, T.F. Jenkins, M.E. Walsh, Protocol for the Characterization of Explosive-Contaminated Sites, Defense Research Establishment Department of National Defense, Valcartier, Quebec, Canada, 1998 DREV-R-9721.

[15] S. Thiboutot, G. Ampleman, A.D. Hewitt, Guide for Characterization of Sites Contaminated with Energetic Materials, U.S. Army Corps of Engineers, Environmental Research and Development Center, Cold Regions Research and Engineering Laboratory, Hanover, NH, 2002 ERDC/CRREL Technical Report TR02-1.

[16] USEPA, SW-846 method 3050B: acid digestion of sediments, sludges, and soils, Test Methods for Evaluating Solid Waste, Physical/Chemical Methods, U.S. Environmental Protection Agency, Office of Solid Waste and Emergency Response, Washington, DC, 1996http://www.epa.gov/osw/hazrad/testmethods/sw846/pdfs/ 3050b.pdf.

[17] USEPA, Method 8330B: nitroaromatics, nitramines, nitrate esters by high performance liquid chromatography (HPLC), Test Methods for Evaluating Solid Waste, Physical/Chemical Methods, Office of Solid Waste and Emergency Response, U.S Environmental Protection Agency, Washington, DC, 2006 SW-846.

[18] USACE, Implementation of Incremental Sampling (IS) of Soil for the Military Munitions Response Program, Environmental and Munitions Center of Expertise, Department of the Army, Huntsville Center, Corps of Engineers, Huntsville, AL, 2009 Interim Guidance Document (IGD) 09-02.

[19] P.M. Gy, Sampling of Particulate Materials: Theory and Practice, Elsevier Scientific Publishing Company, New York, NY, 1982.

[20] P.M. Gy, Sampling of Heterogeneous and Dynamic Material Systems, Elsevier Scientific Publishing Company, New York, NY, 1992.

[21] P.M. Gy, Sampling for Analytical Purposes, John Wiley \& Sons, New York, NY, 1999.

[22] F.F. Pitard, Pierre Gy's Sampling Theory and Sampling Practice: Heterogeneity, Sampling Correctness, and Statistical Process Control, CRC Press, Boca Raton, Florida, 1993.

[23] Florida, Draft Incremental Sampling Methodology (ISM) Guidance, Florida Department of Environmental Protection, Bureau of Waste Cleanup, Tallahassee, FL, 2013.

[24] Alaska, Draft Guidance on MULTI INCREMENT Soil Sampling, Alaska Department of Environmental Conservation, Division of Spill Preventions and Response, Contaminated Sites Program, 2009.

[25] Hawaii, Technical Guidance Manual, Hawaii Department of Health, Office of Hazard Evaluation and Emergency Response, 2008, http://www.hawaiidoh.org/.

[26] J. Clausen, T. Georgian, K. Gardner, T. Douglas, Inadequacy of conventional grab sampling for remediation decision-making for metal contamination at small-arms ranges, Bull. Environ. Contam. Toxicol. 100 (1) (2018) 147-154, https://doi.org/ 10.1007/s00128-017-2255-7.

[27] J.P. Boudreault, J.S. Dubé, M. Sona, E. Hardy, Analysis of procedures for sampling contaminated soil using Gy's sampling theory and practice, Sci. Total Environ. 425 (2012) 199-207.

[28] B.J. Mason., Preparation of Soil Sampling Protocols: Sampling Techniques and Strategies, U.S. Environmental Protection Agency, Las Vegas, NV, 1992 EPA/600/ SR-92/128.

[29] T.R. Peacock, Soil sample preparation, in: J.E. TaggertJr (Ed.), Analytical Methods for Chemical Analysis of Geologic and Other Materials, Denver, CO, 2002 U.S. Geological Survey, Open-File Report 02-0223 http://pubs.usgs/gov/of/2002/ofr 02-0223/OFR-02-0223.pdf.

[30] USEPA, SW-846 method 3051A: microwave assisted acid digestion of sediments, sludges, soils, and oils, Test Methods for Evaluating Solid Waste, Physical/Chemical Methods, U.S. Environmental Protection Agency, Office of Solid Waste and Emergency Response, Washington, DC, 1996.

[31] USEPA, SW-846 method 3052: microwave assisted acid digestion of siliceous and organically based matrices, Test Methods for Evaluating Solid Waste, Physical/ Chemical Methods, U.S. Environmental Protection Agency, Office of Solid Waste and Emergency Response, Washington, DC, 1996.

[32] J. Clausen, T. Georgian, K. Gardner, T. Douglas, Optimization of field and laboratory sample processing for characterization of metallic residues at military training ranges, Bull. Environ. Contam. Toxicol. 100 (5) (2018) 603-608, https://doi.org/ 10.1007/s00128-018-2311-y.

[33] J.-S. Dubé, M. Sona, B. J.-P, E. Hardy, Influence of particle size and grinding on measurement of trace metal concentration in urban anthropogenic soils, J. Environ. Eng. 140 (6) (2014), https://doi.org/10.1061/(ASCE)EE.1943-7870.0000825.

[34] M.E. Walsh, C.A. Ramsey, T.F. Jenkins, The effect of particle size reduction on sub sampling variance for explosives residues in soil, Chemosphere 49 (2002) 1265-1271.

[35] M.E. Walsh, C.A. Ramsey, S. Taylor, A.D. Hewitt, K. Bjella, C.M. Collins, Sub sampling variance for 2,4-DNT in firing point soils, Soil Sedim. Contam. 16 (5) (2007) 459-472.

[36] H.L. Hartman, SME Mining Engineering Handbook: Vol.2, in: W. Seeley (Ed.), Mudd Memorial Fund of AIME. Society for Mining, Metallurgy and Exploration, Littleton, CO, 1992.

[37] X. Cao, L.Q. Ma, M. Chen, D.W. Hardison, W.G. Harris, Lead transformations and distribution in the soils of shooting ranges in Florida, USA, Sci. Total Environ. 307 (2003) 179-189.

[38] J.R. Craig, D. Edwards, J.D. Rimstidt, P.F. Scanlon, T.K. Collins, O. Schabenberger, J.B. Birch, Lead distribution on a public shotgun range, Environ. Geol. 41 (2002) 873-882.

[39] D.R. Felt, A.J. Bednar, T. Georgian, The effects of grinding methods on metals concentrations in soil, Talanta 77 (2008) 380-387.

[40] J.L. Clausen, J. Kaste, M. Ketterer, N. Korte, Sample preparation and digestion considerations for determining metal deposition at small-arms ranges, Int. J. Environ. Anal. Chem. 90 (12) (2010) 903-921, https://doi.org/10.1080/ 03067310903353495

[41] J.S. Dubé, J.-P. Boudreault, R. Bost, M. Sona, F. F. Duhaime, Y. Éthier, Representativeness of laboratory sampling procedures for the analysis of trace metals in soil, Environ. Sci. Pollut. Res. 22 (15) (2015) 11862-11876, https://doi. org/10.1007/s11356-015-4447-1C.

[42] L. Petersen, C.K. Dahl, K. Esbensen, Representative mass reduction in sampling - a critical survey of techniques and hardware, Chemometr. Intell. Lab. Syst. 74 (2004) 95-114, https://doi.org/10.1016/j.chemolab.2004.03.020. 


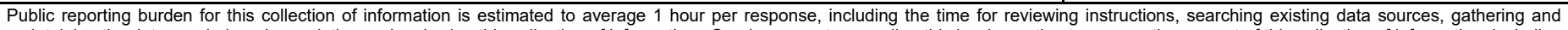

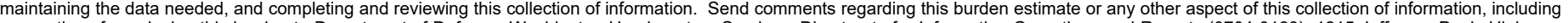

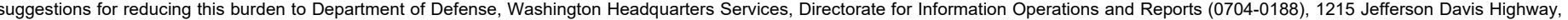

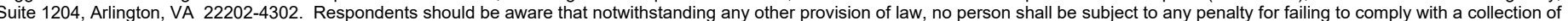
information if it does not display a currently valid OMB control number. PLEASE DO NOT RETURN YOUR FORM TO THE ABOVE ADDRESS.

\section{information if it does not display a currently valid OMB control number. PLEASE DO NOT RETURN YOUR FORM TO THE ABOVE ADDRESS.}

\begin{tabular}{l|l|l}
$\begin{array}{l}\text { 1. REPORT DATE (DD-MM-YYYY) } \\
\text { July } 2021\end{array}$ & $\begin{array}{c}\text { 2. REPORT TYPE } \\
\text { Final }\end{array}$ & 3. DATES COVERED (From - To) \\
\hline
\end{tabular}

\section{TITLE AND SUBTITLE}

5a. CONTRACT NUMBER

Effects of milling on the metals analysis of soil samples containing metallic residues

5b. GRANT NUMBER

5c. PROGRAM ELEMENT NUMBER

6. AUTHOR(S)

5d. PROJECT NUMBER

Jay L. Clausen, Samuel A. Beal, T. Georgian, K.H. Gardner, T.A. Douglas, and Ashley M. Mossell

5e. TASK NUMBER

5f. WORK UNIT NUMBER

7. PERFORMING ORGANIZATION NAME(S) AND ADDRESS(ES)

8. PERFORMING ORGANIZATION REPORT NUMBER

See next page.

ERDC/CRREL MP-21-12

9. SPONSORING / MONITORING AGENCY NAME(S) AND ADDRESS(ES)

Headquarters, U.S. Army Corps of Engineers

441 G Street NW

Washington, DC 20314-1000

10. SPONSOR/MONITOR'S ACRONYM(S)

USACE

11. SPONSOR/MONITOR'S REPORT NUMBER(S)

\section{DISTRIBUTION / AVAILABILITY STATEMENT}

Approved for public release; distribution is unlimited.

\section{SUPPLEMENTARY NOTES}

This article was originally published online in the Microchemical Journal on 8 January 2020.

This article was based on a privately funded $\mathrm{PhD}$ dissertation presented to the University of New Hampshire. The research did not receive any specific grant from funding agencies in the public, commercial, or not-for-profit sectors.

\section{ABSTRACT}

Metallic residues are distributed heterogeneously onto small-arms range soils from projectile fragmentation upon impact with a target or berm backstop. Incremental Sampling Methodology (ISM) can address the spatially heterogeneous contamination of surface soils on small-arms ranges, but representative kilogram-sized ISM subsamples are affected by the range of metallic residue particle sizes in the sample. This study compares the precision and concentrations of metals in a small-arms range soil sample processed by a puck mill, ring and puck mill, ball mill, and mortar and pestle prior to analysis. The ball mill, puck mill, and puck and ring mill produced acceptable relative standard deviations of less than 15\% for the anthropogenic metals of interest $(\mathrm{Lead}(\mathrm{Pb})$, Antimony $(\mathrm{Sb})$, Copper $(\mathrm{Cu})$, and Zinc $(\mathrm{Zn})$ ), with the ball mill exhibiting the greatest precision for $\mathrm{Pb}, \mathrm{Cu}$, and $\mathrm{Zn}$. Precision by mortar and pestle, without milling, was considerably higher $(40 \%$ to $>100 \%)$ for anthropogenic metals. Media anthropogenic metal concentrations varied by more than $40 \%$ between milling methods, with the greatest concentrations produced by the puck mill, followed by the puck and ring mill and then the ball mill. Metal concentrations were also dependent on milling time, with concentrations stabilizing for the puck mill by $300 \mathrm{~s}$ but still increasing for the ball mill over $20 \mathrm{~h}$. Differences in metal concentrations were not directly related to the surface area of the milled sample. Overall, the tested milling methods were successful in producing reproducible data for soils containing metallic residues. However, the effects of milling type and time on concentrations require consideration in environmental investigations.

\section{SUBJECT TERMS}

Soil processing, Metals, Small-arms ranges, Incremental sampling

\begin{tabular}{|c|c|c|c|c|c|}
\hline \multicolumn{3}{|c|}{ 16. SECURITY CLASSIFICATION OF: } & \multirow{2}{*}{$\begin{array}{c}\text { 17. LIMITATION } \\
\text { OF ABSTRACT } \\
\text { SAR }\end{array}$} & \multirow{2}{*}{$\begin{array}{l}\text { 18. NUMBER } \\
\text { OF PAGES } \\
\qquad 14\end{array}$} & \multirow{2}{*}{$\begin{array}{l}\text { 19a. NAME OF RESPONSIBLE } \\
\text { PERSON } \\
\begin{array}{l}\text { 19b. TELEPHONE NUMBER (include } \\
\text { area code) }\end{array}\end{array}$} \\
\hline $\begin{array}{l}\text { a. REPORT } \\
\text { Unclassified }\end{array}$ & $\begin{array}{l}\text { b. ABSTRACT } \\
\text { Unclassified }\end{array}$ & $\begin{array}{l}\text { c. THIS PAGE } \\
\text { Unclassified }\end{array}$ & & & \\
\hline
\end{tabular}


Cold Regions Research and Engineering Laboratory

U.S. Army Engineer Research and Development Center

72 Lyme Road

Building 4070

Hanover, NH 0755

Fort Wainwright, AK 99703

U.S. Army Corps of Engineers

1616 Capital Avenue

Omaha, NE 68102

Department of Civil and Environmental Engineering

University of New Hampshire

Durham, NH 03824 